\title{
NUMERICAL INVESTIGATION OF HEAT TRANSFER ENHANCEMENT IN HEAT SINKS USING MULTIPLE ROWS VORTEX GENERATORS
}

\author{
Shayan Fathi, Mohamad Eftekhari Yazdi*, Armen Adamian \\ Department of Mechanical Engineering, Central Tehran Branch, Islamic Azad University, Tehran, Iran \\ e-mail: fathiphd@gmail.com; moh.eftekhari_yazdi@iauctb.ac.ir ( ${ }^{*}$ correspondingauthor); arm.adamian@iauctb.ac.ir
}

\begin{abstract}
This study investigates the application of multiple rows vortex generators for heat transfer improvement of heat sinks. At first, five different geometries of heat sinks are investigated. After choosing the optimum heat sink geometry based on the heat transfer performance and pressure drop characteristic, application of multiple rows of vortex generators is investigated for heat transfer improvement. The effect of different parameters including the number of vortex generator rows, distance between them and also their inclination angle on the heat transfer performance of heat sinks are studied as well. Numerical investigations are done based on the finite volume method. The numerical computations have been validated with available experimental data. The results show that the wavy form of geometry of heat sinks has the best heat transfer performance among the considered ones. This geometry showed an $11 \%$ increase in the heat transfer rate compared to a conventional plate-fin heat sink. In addition, by using one, two and three rows vortex generators, thermal performance of heat sink has been improved by 10,14 and $16 \%$, respectively.
\end{abstract}

Keywords: computation fluid dynamics, heat sink, multiple rows vortex generator, heat transfer

\section{Introduction}

Today, electronic industries are considered as one of the most important, basis and main fields in the world. There are lots of different sub-sets of electronic industries which are widely used in a variety of engineering areas. Electronic packaging are applied in main industries such as military, space science, telecommunications, data centers, medicine science and etc.

That is the fact, with the advancement of new technologies, the size of recent electronic devices are reducing more and more. Hence, heat dissipation of them is increasing, so the problem of electronic cooling has become a critical issue in this area. By increasing the power of microprocessors, it is needed to benefit from more efficient cooling techniques to cool down higher heat rates. To keep the working temperature of today's electronic devices within safe limits, many cooling methods have been evolved recently. Nowadays, because of the conventional cooling techniques limitations, new designs are investigated to increase and control heat flux to keep the working temperatures in an acceptable range (Micheli et al., 2016; Costello and Demulliez, 2013; Khanna et al., 1999; Goldmann et al., 1997; Wong et al., 1997; Ibitayo, 2008; Masuko and Takeda, 2009; Shanmugan et al., 2014). Heat sinks are one of the efficient ways for cooling electronic integrated components and controling them to work under the allowable operational temperature.

Meanwhile, different geometries of heat sinks are provided by many industries to cool down the aforementioned electronic components. Nevertheless, in many cases, an appropriate heat sink geometry will be the vital need under transient and steady heat generation (Jain et al., 2009). Till today, many investigations have been performed on thermal performance of heat sinks. Poulikakos and Bejan (1982) investigated behavior and role of the pins in different geometry of 
heat sinks. They found that trapezoidal, rectangular and triangular pin-fin heat sinks are the best geometries in minimization of entropy generation. Culham and Muzychka (2001) considered entropy minimization in flat heat sinks. They studied five different geometries of heat sinks considering the effect of the number of fins on the heat transfer rate, pressure drop and contact resistance. In their study, the optimum number of fins and also the most efficient flow speed passing through the heat sinks were reported. Feng et al. (2018) designed a kind of heat sink which included a combination of long and short fins arranged perpendicularly to obtain the maximum free convection rate. The study results showed a $15 \%$ convective heat transfer increase compared to a plate-fin heat sink. Lee et al. (2016) experimentally investigated the influence of fin numbers on natural convection heat transfer from vertical cylinders with triangular fins. They found that by decreasing spaces among the fins, the Nusselt number is reduced slowly. Joo and Kim (2015) studied the effect of width and length of fins on heat transfer and pressure drop of a fin-pin heat sink with different arrangements. It was found that by reducing the length and width of pin-fins, heat dissipation increased significantly.

Hamadneh et al. (2013) reported the optimum pin heat sink geometry based on thermal performance by minimizing entropy generation and also by comparison with three different cross section areas for plates (circular, quadrangular and oval). Salwe et al. (2014) investigated numerically the thermal performance of pin fin heat sinks and compared the results with the normal ones in forced flow. It was found that pin fin heat sinks benefitted from better thermal performance. Until now, some investigations have been done on the role of vortex generators in thermal performance improvement in different electrical devices. As an example, Fiebig (1995) conducted an investigation experimentally and numerically to enhance thermal performance and to decrease pressure drop of the internal flow in tubes. Torji et al. (2002) investigated heat transfer increase accompanying pressure-loss reduction with Winglet-type vortex generators for fin-tube heat exchangers with different arrangements. Downstream vortex generators represented a major effect on heat transfer enhancement by disturbing the thin boundary layer at the wall, so increasing the local Nusselt number as shown by Habchi et al. (2012). In other words, adding hemispherical protrusions among the vortex generator arrays enhanced heat transfer with only a small rise in the pressure drop. This increase in local heat transfer was caused by increasing the temperature gradients very close to the heated wall.

As it was discussed, many investigations have been done numerically and experimentally on different geometries of heat sinks. However, there is not sufficient information about considering the effect of multiple vortex generator rows for improvement of heat transfer rate in heat sinks for electronic devices cooling. In the present study, first of all, five different heat sink geometries are compared in terms of the heat transfer efficiency and pressure drop. Then, the effect of multiple row vortex generators are investigated in terms of finding the optimum heat sink geometry.

\section{Governing equations}

The governing equations for fluid flow and heat transfer in terms of the continuity equation in an incompressible flow, Navier-Stokes equations as well as energy and momentum equations are solved.

The continuity equation is considered as

$$
\nabla \cdot \mathbf{V}=0
$$

in which $\mathbf{V}$ is velocity vector. With consideration to incompressible flow regime and constant viscosity, the form of the Navier-Stockes equation will be as in the following

$$
\rho \frac{D \mathbf{V}}{D t}=\rho \mathbf{f}-\nabla P+\mu \nabla^{2} \mathbf{V}
$$


where $P$ is pressure, $\mathbf{f}$ is body force and $\mu$ is dynamic viscosity. The energy equation with a constant conduction coefficient will be defined as

$$
C_{p}\left(\rho u \frac{\partial T}{\partial x}+\rho v \frac{\partial T}{\partial y}\right)=k\left(\frac{\partial^{2} T}{\partial x^{2}}+\frac{\partial^{2} T}{\partial y^{2}}\right)
$$

where $\rho$ is density. Also, the thermal resistance of the heat sink will be defined as below

$$
R=\frac{T_{\text {mean }}-T_{\infty}}{Q}
$$

where $T_{\text {mean }}$ is the average temperature of the heat sink base plate, $T_{\infty}$ is temperature of the coolant, and $Q$ is the applied heat flux. Also, the Reynolds number is defined as

$$
\operatorname{Re}=\frac{u L}{\nu}
$$

where $u$ is velocity of the fluid, $L$ is a characteristic linear dimension and $\nu$ is kinematic viscosity of the fluid.

\section{Geometry and meshing}

In the present investigation, firstly, the thermal efficiency of five different geometries of heat sinks have been considered for simulation. A conventional plate-rectangular fin heat sink is the first heat sink which is shown in Fig. 2a. The second heat sink geometry is a plate-pin fin heat sink that is shown in Fig. 2b. A combination of the plate-rectangular fin and the plate-pin fin heat sink is the third geometry which is shown in Fig. 2c. The forth geometry is a plate-wavy fin heat sink which is shown in Fig. 2d. Also, a combination of the plate-wavy fin with the plate-pin fin heat sink, the fifth geometry, is shown in Fig. 2e. The dimensions of heat sinks based on the schematic in Fig. 1 are given in Table 1. Overall dimensions and surface area of different geometries of the heat sinks are the same. The wind tunnel test section has dimensions of $150 \mathrm{~mm} \times 150 \mathrm{~mm} \times 1300 \mathrm{~mm}$. The heat sinks are placed in a distance of $900 \mathrm{~mm}$ from the wind tunnel entrance.

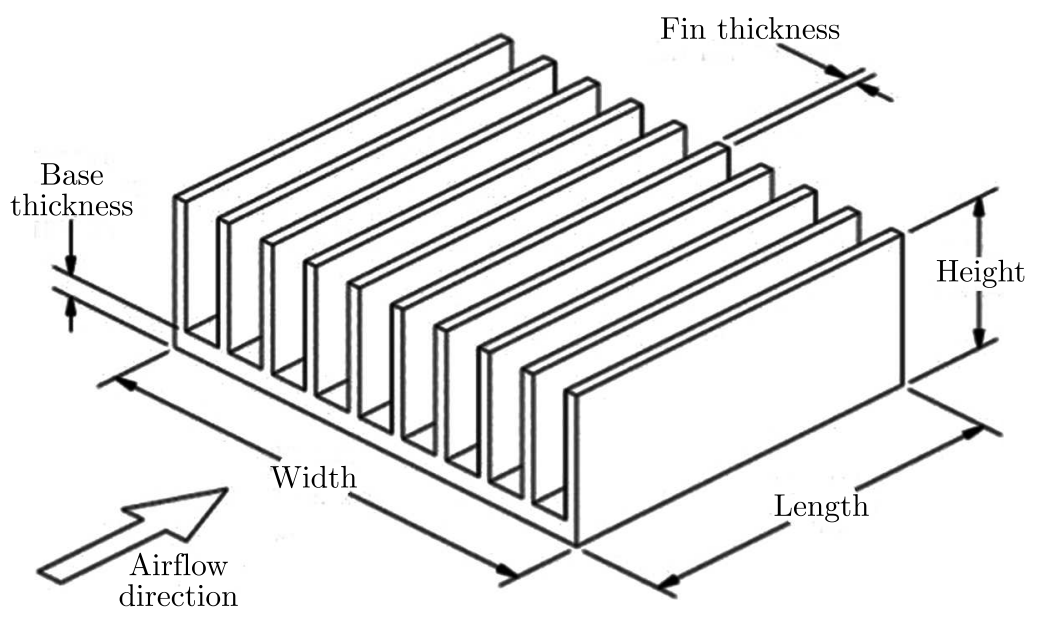

Fig. 1. Schematic of the conventional plate-fin heat sink

Mesh grids of different heat sinks are presented in Fig. 2. In this study, after comparison of different studied heat sink geometries and choosing the best one from the thermal performance and pressure drop aspects, the selected heat sink is considered with a multiple rows vortex generator for achieving better heat transfer performance. The proposed geometry of the triangular 
Table 1. Dimensions of the base simulated heat sink (refer to Fig. 1)

\begin{tabular}{|l|c|}
\hline \multicolumn{1}{|c|}{ Parameter } & Amount $[\mathrm{mm}]$ \\
\hline \hline Width $W_{H S}$ & 63.5 \\
\hline Length $L_{H S}$ & 63.5 \\
\hline Height $H_{H S}$ & 18.3 \\
\hline Fin thickness $t$ & 1.27 \\
\hline Channel width $g$ & 2.54 \\
\hline Base plate thickness $b$ & 2.54 \\
\hline
\end{tabular}

(a)

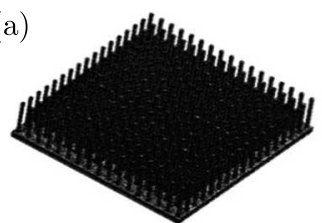

(c)

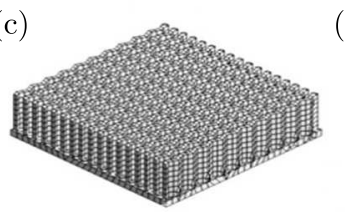

(e) (b)

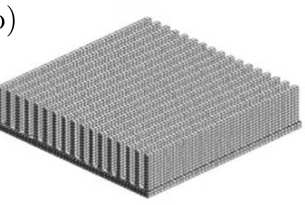

(d)

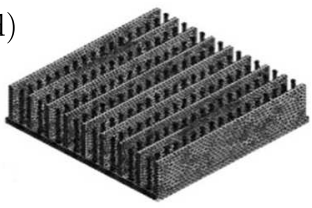

1/

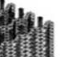

Fig. 2. Mesh grid of five different heat sinks

vortex generator has been shown in Fig. 3. Different arrangements of multiple rows of vortex generators in front of heat sinks are presented in Fig. 4. In this regard, three different arrangements of vortex generators in one, two and three rows against the air flow passing throw the heat sink have been considered. Also, effects of different arrangements of the three rows vortex generators are investigated, which is shown in Fig. 4. Furthermore, dimensions of the studied base vortex generator is are given in Table 2 . Because of the complexity of different investigated geometries, the mesh grid of each part is different one from another. After investigating mesh independency, the total number of mesh grids is considered to be around 1.2 million.
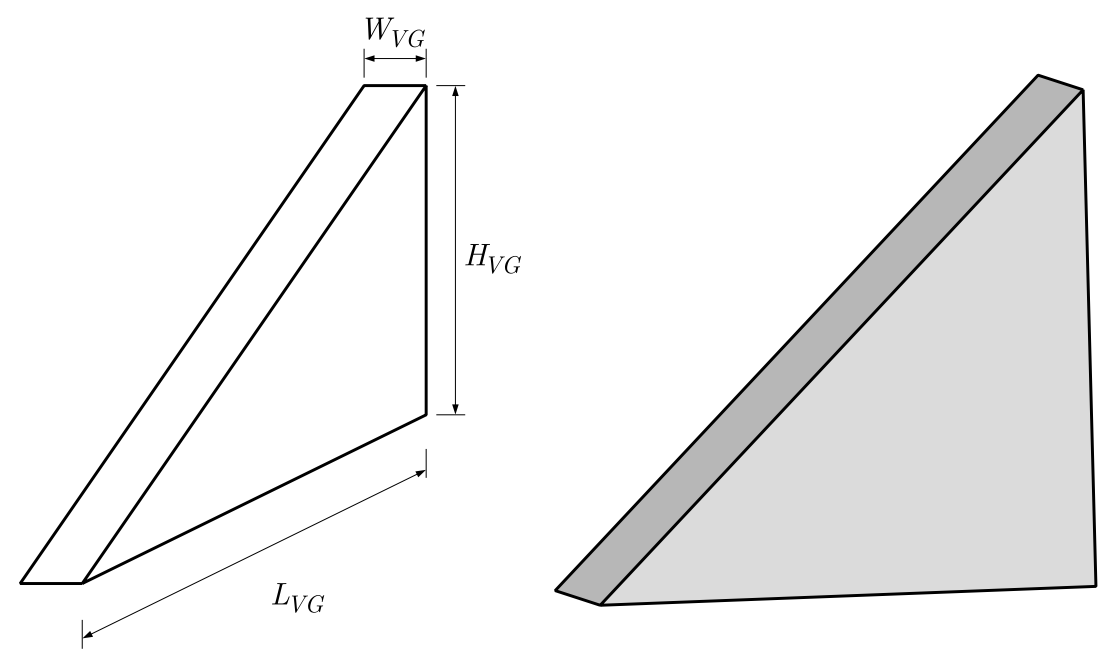

Fig. 3. Geometry of triangular vortex generators 
(a)
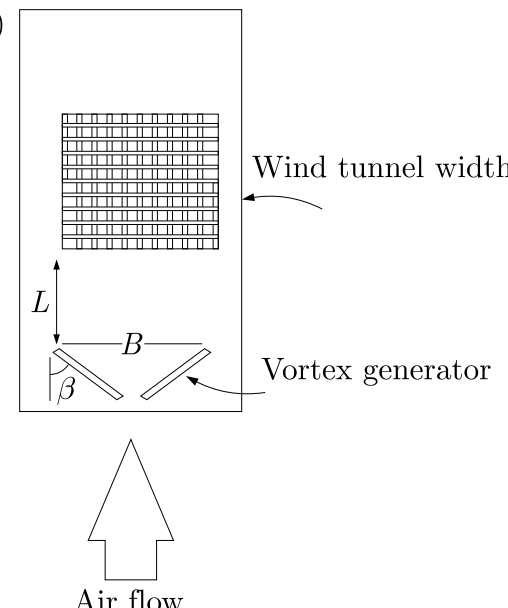

(b)

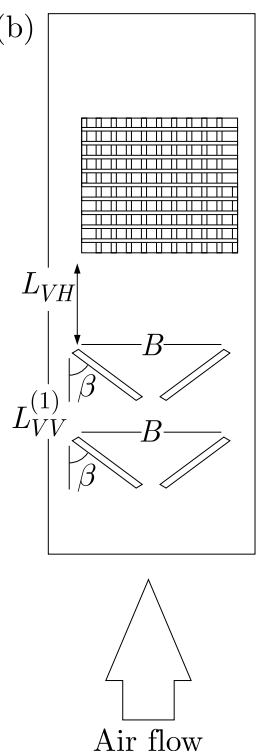

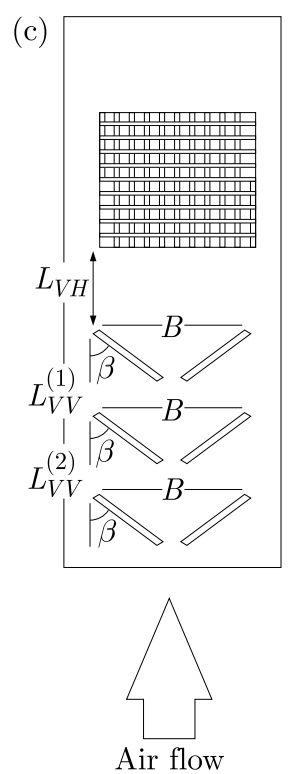

Fig. 4. Schematic of different arrangements of vortex generators

Table 2. Dimensions of the base vortex generator (refer to Fig. 3)

\begin{tabular}{|l|c|}
\hline \multicolumn{1}{|c|}{ Parameter } & Amount $[\mathrm{mm}]$ \\
\hline \hline Width $W_{V G}$ & 2 \\
\hline Long $L_{V G}$ & 9.15 \\
\hline Height $H_{V G}$ & 9.15 \\
\hline
\end{tabular}

\section{Numerical simulation}

In this study, for the purpose of numerical simulations, ANSYS Fluent software, which is based on finite volume method, is used. Different geometries are modeled by SolidWorks software. In the present investigation, simulations are done for analyzing thermal performance of five different heat sink geometries. Then, different arrangements of vortex generators are considered based on their thermal performance. For solving the problem, different equations of continuity, momentum and energy for the fluid flow have been solved. The fluid flow is turbulent, and there is fluid swirl on the vortex generators. For considering the effects of swirl on vortex generators, an RNG $K-\varepsilon$ turbulent model is considered in the simulation. The accuracy of the problem solving for convergence is $10^{-6}$. Simulations have been done under steady state conditions. According to the type of flow, the SIMPLE algorithm is used to discretize the coupled velocity and pressure equations. The momentum equation has been discretized in the Second Order Upwind for better discretization accuracy.

According to the fact that the heat flux is applied to the surface below the heat sink, the conduction equation inside the solid geometry of it is solved. For investigation of the independency of the results on the number of geometry meshes, the problem has been solved for different mesh grid numbers. In mesh independency evaluation, the dimensions are as provided in Tables 1 and 2. After mesh independency analysis, the number of mesh grids is considered to be near to 1200000 .

In the current study, the air and aluminum are considered as the coolant fluid and the material of the heat sink, respectively. Furthermore, the heat flux and fluid flow velocities are $7 \mathrm{Kw} / \mathrm{m}^{2}$ and $1-5 \mathrm{~m} / \mathrm{s}$, respectively. In this study, after comparison of five heat sink geometries 
with each other, the effect of using multiple rows of vortex generators using the optimum selected heat sink geometry, in order to get greater improvement in the thermal performance, has been investigated. Moreover, according to the dimensions specified in Figs. 6 and 8, the effects of vortex generator parameters such as height and lengths $\left(L_{V G}\right.$ and $\left.H_{V G}\right)$, distance between two vortex generators $\left(B\right.$, from $15 \mathrm{~mm}$ to $85 \mathrm{~mm}$ ), angle of vortex generators $\left(\beta\right.$, from $30^{\circ}$ to $60^{\circ}$ ) and distance between the vortex generators and heat sinks ( $L_{V}$, from $10 \mathrm{~mm}$ to $67 \mathrm{~mm}$ ) and also the arrangements of vortex generators in one, two and three rows with the constant distance of $L=10 \mathrm{~mm}$ from each other have been studied. Meanwhile, the effects of vortex generators distances from each other in two and three rows arrangements $\left(L_{V V}(1)\right.$ and $\left.L_{V V}(2)\right)$ are discussed as well.

\section{Validation of the results}

An experimental investigation was done by Loh and Chou (2004), which is used for validating the present study. In their work, a theoretical, experimental and numerical investigation was conducted on geometry of the plate-rectangular fin heat sink. In that experimental study, the plate-rectangular fin heat sink was chosen with specifications provided in Table 1. Experimental tests were done in the speed range of $1 \mathrm{~m} / \mathrm{s}$ to $4 \mathrm{~m} / \mathrm{s}$. The comparison between the experimental study on geometry of the plate-rectangular fin heat sink and the current numerical investigation with the same geometry is shown in Fig. 5. The dimension of the validation case is according to Table 3. Analyzing the data one observes that the results of the present numerical study are very similar to the experimental results with the mean squared error of about $6 \%$ only, which represents firmly that the accuracy of the current study could be totally reliable.

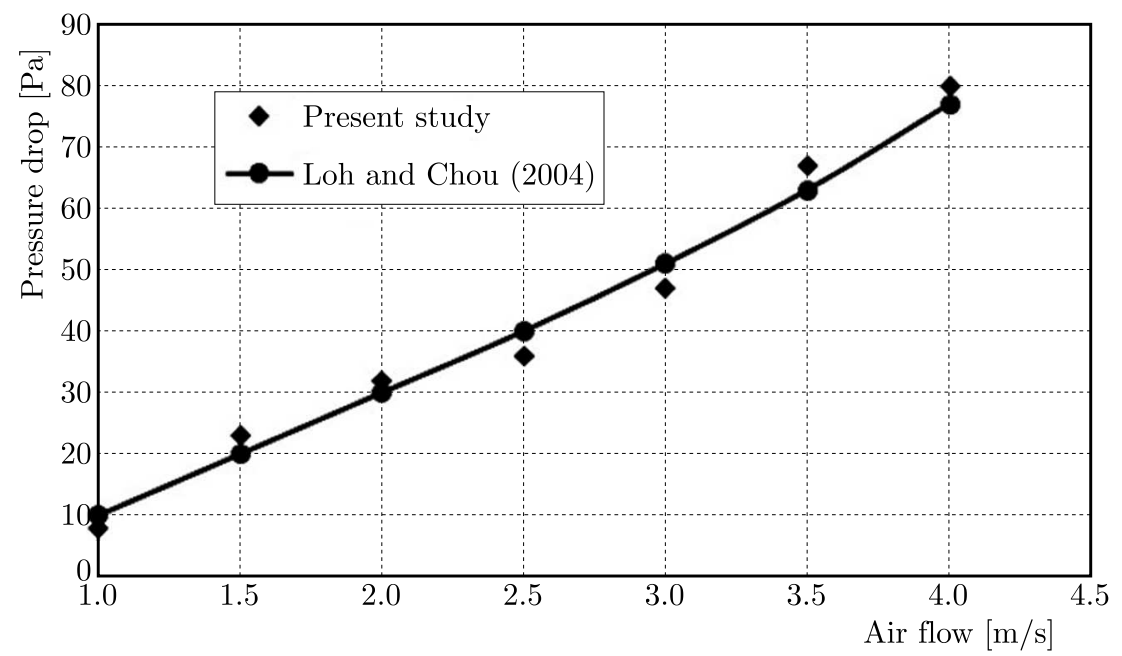

Fig. 5. Comparison between current results and the results by Loh and Chou (2004)

Table 3. Dimensions of the base simulated heat sink (refer to Fig. 1) (Loh and Chou, 2004)

\begin{tabular}{|l|c|}
\hline \multicolumn{1}{|c|}{ Parameter } & Amount $[\mathrm{mm}]$ \\
\hline \hline Width $W_{H S}$ & 126 \\
\hline Length $L_{H S}$ & 75 \\
\hline Height $H_{H S}$ & 63 \\
\hline Fin thickness $t$ & 1 \\
\hline Channel width $g$ & 1.55 \\
\hline Base plate thickness $b$ & 7 \\
\hline
\end{tabular}




\section{Results and discussion}

Figure 6 shows the temperature distribution on the surfaces of different heat sinks for five different geometries and the Reynolds number of 20000. As it is shown, the temperature distribution on heat sink surfaces for various geometries differ from each other. Temperature changes from high to low from the beginning to the end of the heat sink. This is because of the cooling fluid direction from the beginning to the end of it. Moreover, the minimum surface temperature belongs to the geometries of heat sinks d, a, c, e and b, respectively. Hence, geometry of heat sink (d), which is a plate-wavy fin heat sink, has the most appropriate thermal performance and the least heat sink surface temperature. Figure 7 shows the thermal resistance of different heat sink geometries. According to Figs. 6 and 7, it is shown that geometry of heat sink (d), which is a plate-wavy fin heat sink, has the best thermal performance and simultaneously the least thermal resistance. Also, geometry of heat sink (d) in comparison to the conventional plate-rectangular fin heat sink, has about $11 \%$ less thermal resistance.

(a)

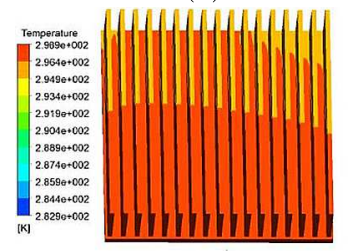

(c)

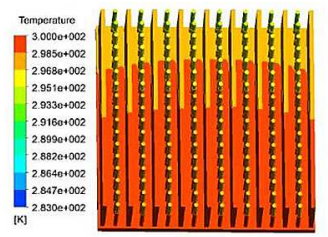

(b)

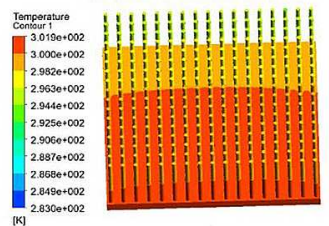

(d)

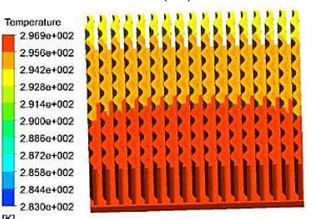

(e)

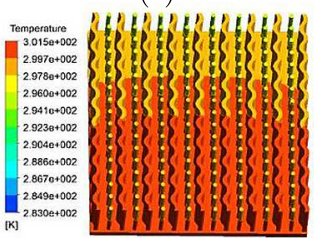

Fig. 6. Temperature distribution on surfaces of different heat sinks for the Reynolds number of 20000

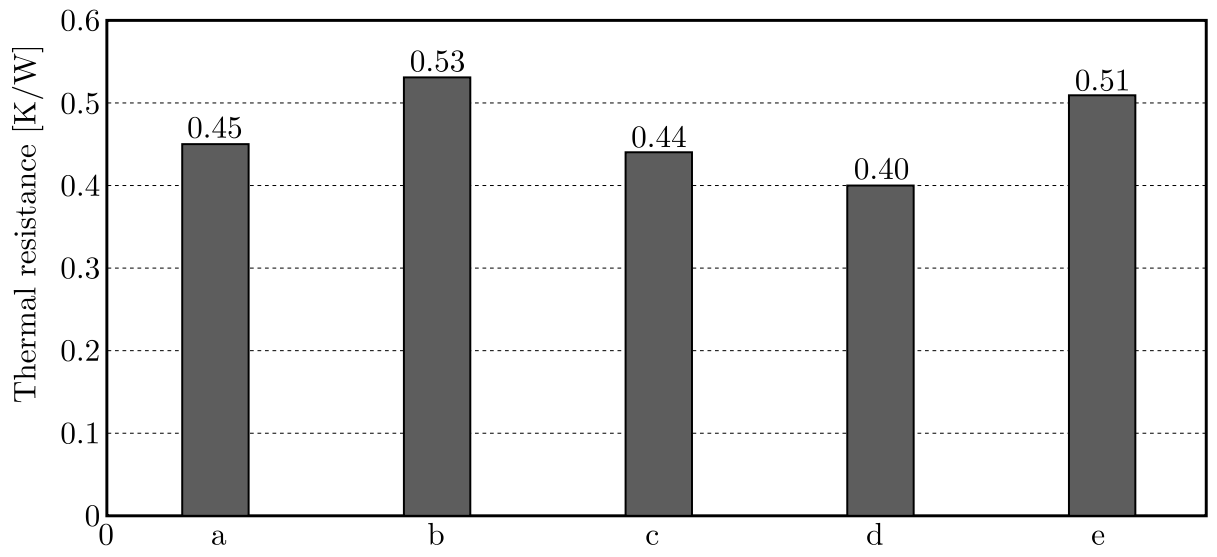

Fig. 7. Thermal resistance for different geometries of heat sinks 
For a more efficient design of the heat sinks, it is required to have less thermal resistance and pressure drop as well. Figure 8 shows the pressure distribution on heat sinks for different geometries at $\operatorname{Re}=20000$. As it is shown, the lowest pressure drop belongs to heat sinks e, a, b, $c$ and d, respectively. So, geometry of heat sink (e), which is a combination of the plate-pin fin with the plate-wavy fin heat sink, has the least pressure drop. It means that this heat sink needs the minimum power and dimension of the required fan for cooling purposes. Consequently, it will be more affordable, particularly in the cases which have financial limitations.

(a)

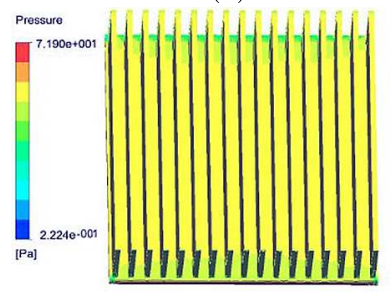

(c)

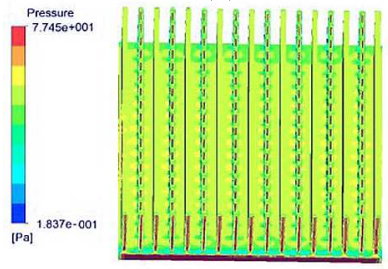

(b)

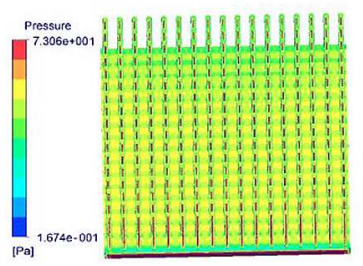

(d)

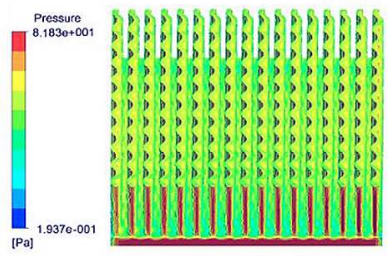

(e)

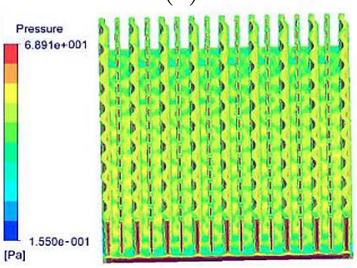

Fig. 8. Pressure distribution for different heat sink geometries at $\mathrm{Re}=20000$

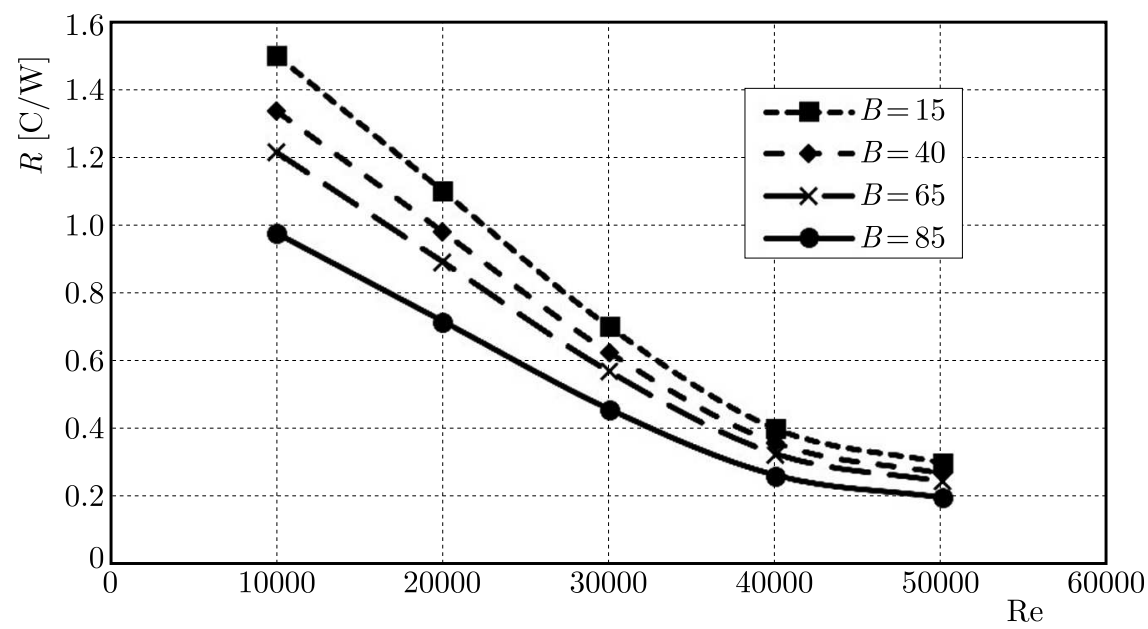

Fig. 9. Effect of distance between two vortex generators on heat sink thermal performance

Figure 9 shows the effect of distance change between two vortex generators on heat sink thermal performance. It can be seen that thermal resistance decreases with an increase in Re number. This is notable that, at higher Reynolds numbers, the thermal contact decreasing rate will be low. Also, thermal resistance reduces when the amount of $B$ increases. In addition, for 
higher amount of $B$, its change rate is low. So, the thermal resistance increases with an increase of $B$ until it reaches width of the heat sink and then, it remains constant since the fluid is forced to pass the heat sink. By increasing the amount of $B$ more than the heat sink width, the fluid is not limited to heat sink dimensions and passes its sides. So, the thermal resistance remains constant.

Figure 10 shows the effect of distance between the vortex generator and the heat sink on heat sink thermal efficiency. As it has been shown, at lower Reynolds numbers (Re between 10000 and 20000), the effect of vortex generator on heat resistance is significant. At higher Reynolds numbers (Re from 40000 to 50000), the effect of vortex generator length $\left(L_{v h}\right)$ on thermal resistance is insignificant.

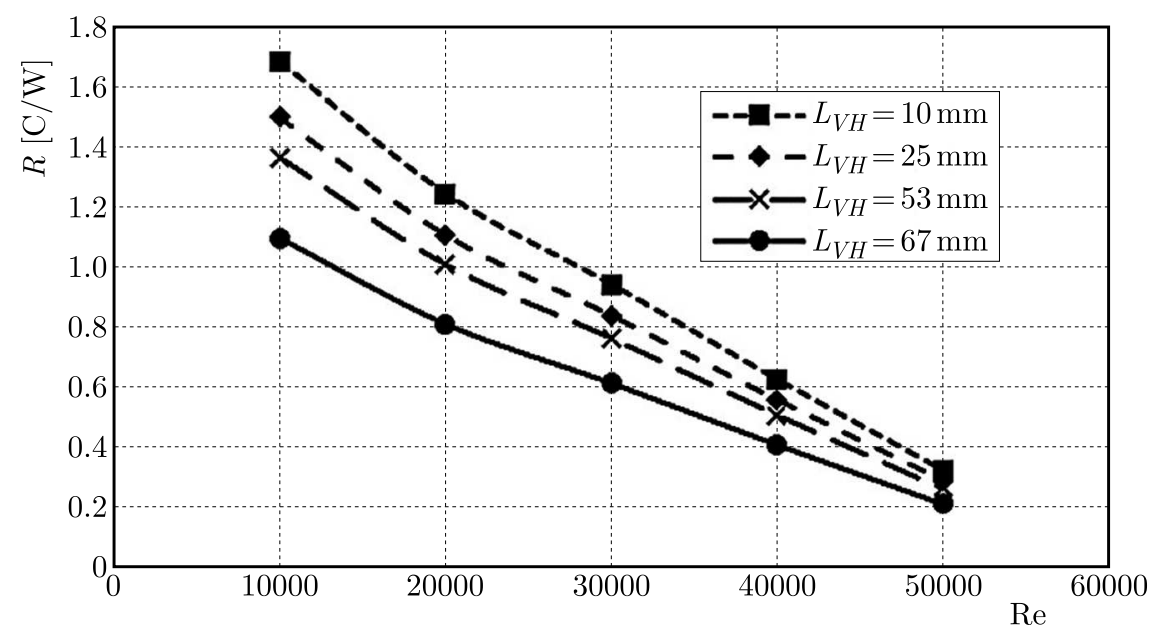

Fig. 10. Effect of vortex generators distance from the heat sink on thermal performance

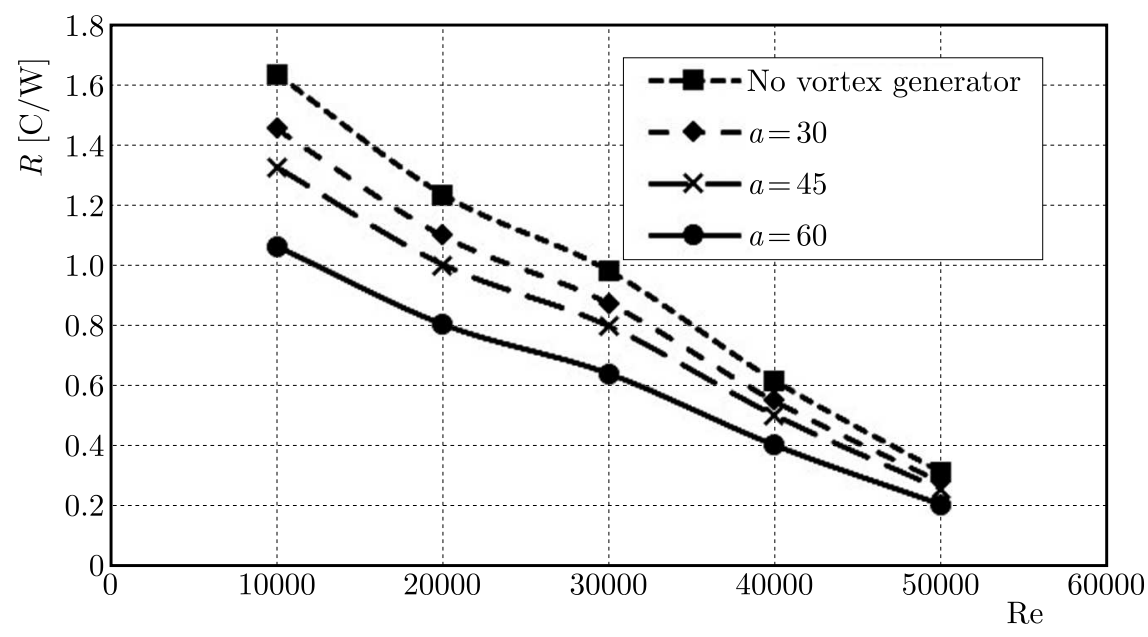

Fig. 11. Effect of the inclination angle of the vortex generator arrangement on thermal performance of the heat sink

Figure 11 shows the effect of vortex generator inclination angle on heat sink thermal performance. As it is shown, thermal resistance of the heat sink decreases with enhancement of the inclination angle of the vortex generator, and it is notable that this reduction is more tangible at lower Reynolds numbers. So, the heat transfer increases while the thermal resistance rate decreases. Also, the effect of vortex generator inclination angle on the thermal resistance is more significant at low Reynolds numbers (Re from 10000 to 20000). At higher Reynolds numbers (Re from 40000 to 50000), the effect of flow swirl on the heat transfer rate is more sensible and 
the effect of vortex generator on the heat transfer rate is less. Figure 12 shows the effect of vortex generator height on heat sink thermal performance. As it has been shown, for all studied heights, an increase in the Re number leads to thermal resistance reduction. It is clear that an increase of vortex generator height would decrease thermal resistance leading to heat transfer rate enhancement. This is because of increasing the face in front of the fluid flow with increasing height of the vortex generator. So, the fluid flow pressure drop across the vortex generator increases and makes a big flow vortex. These vortexes carry more amount of heat from the heat sink surface and more decrease thermal resistance. On the other hand, using vortex generators decreases the available area inside the channel for fluid flow. So, for an equal fluid flow rate, the fluid velocity increases, and this action leads to better thermal performance and less thermal resistance.

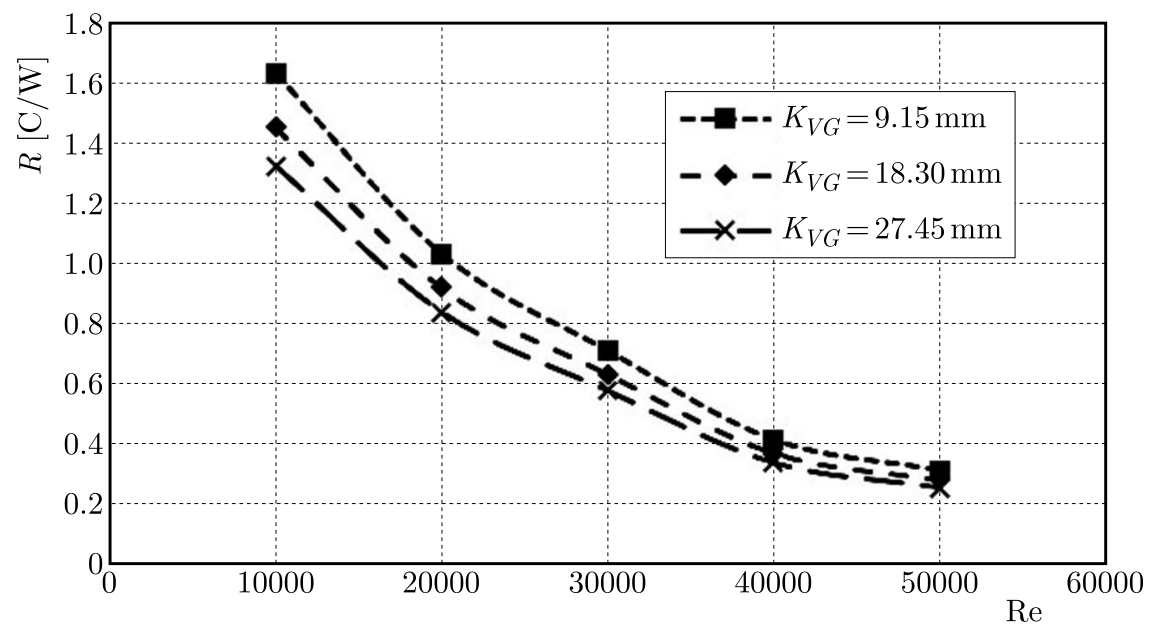

Fig. 12. Effect of vortex generator height on thermal performance of the heat sink

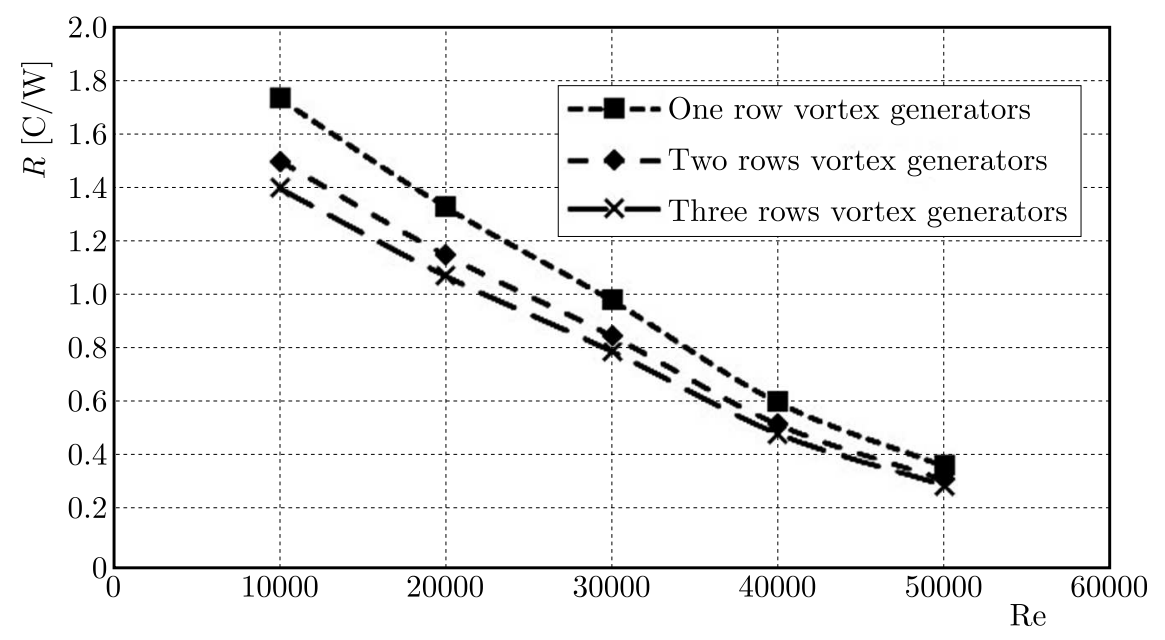

Fig. 13. Effect of the number of vortex generator rows on thermal performance of the heat sink

Figure 13 shows the effect of the vortex generator rows on thermal performance of the heat sink. It has been shown that thermal performance of the heat sink improves as the number of vortex generator rows increase from one to three. Also, it is shown that the thermal performance improvement from one row to two rows vortex generators is more tangible than from two to three rows. Also, it can be seen that two and three rows of vortex generators decrease thermal resistance of heat sinks by about $14 \%$ and $16 \%$, respectively. Figure 13 shows the effect of the number of vortex generator rows on the fluid flow pressure drop. The pressure drop enhances as 
the number of vortex generator rows increases from one to three. Also, the pressure drop rate from one to two rows vortex generators is greater than from two to three vortex generators.

\section{Conclusion}

In the present study, a numerical investigation of the fluid flow regime and heat transfer analysis of five different heat sink geometries has been conducted. For validation purpose, the results of the current study were compared with available experimental results which are compatible with each other with the RMSE error of less than $6 \%$, which shows acceptable accuracy. Heat sink thermal performance and fluid flow pressure drop were considered as two main criteria of the present investigation. Considering the thermal efficiency parameter, a heat plate-wavy fin heat sink was chosen as the best one. Also, considering the pressure drop as a key parameter, a combination of the plate-pin fin with the plate-wavy fin heat sink has the minimum pressure drop.

After choosing the appropriate geometry of the heat sink, the effect of various arrangements of vortex generators on thermal performance of the optimum selected heat sink was investigated. In this regard, the effects of parameters including height and length of vortex generators, the inclination angle and also the effects of distance between the vortex generators and the heat sink on the heat sink thermal performance were investigated.

\section{References}

1. Costello S., Demulliez M., 2013, Packaging and environmentally induced failures, Hermeticity Testing of MEMS and Microelectronic Packages, Artech House

2. Culham J.R., Muzychka Y.S., 2001, Optimization of plate fin heat sinks using entropy generation minimization, IEEE Transactions on Components and Packaging Technologies, 24, 2, 159-165

3. Feng S., Shi M., Yan H., Sun S., Li F., Lu T.J., 2018, Natural convection in a cross-fin heat sink, Applied Thermal Engineering, 132, 7, 30-37

4. Fiebig M., 1995, Embedded vortices in internal flow: heat transfer and pressure loss enhancement, International Journal of Heat Fluid Flow, 16, 5, 376-388

5. Goldmann L., Howard R., Jeannotte D., 1997, Package reliability, Microelectronics Packaging Handbook, Springer

6. Habchi C., Russeil S., Bougeard D., Harion J.L., Lemenand T., Della Valle D., PeerHOSSAINI H., 2012, Enhancing heat transfer in vortex generator-type multifunctional heat exchangers, Applied Thermal Engineering, 38, 18, 14-25

7. Hamadneh N., Khan W.A., Sathasivam S., Ong H.C., 2013, Design optimization of pin fin geometry using particle swarm optimization algorithm, PloS one, 8, 5, 66-80

8. Ibitayo O., 2008, Evaluation of Various Die-Attachment Materials and Processes for Power Electronics Packaging, Howard University

9. Jain P., Zhou P., Kim C.H., SapatneKar S., 2009, Thermal and power delivery challenges in 3D ICs, [In:] Three Dimensional Integrated Circuit Design: EDA, Design and Microarchitectures, $33-61$

10. Joo Y., Kim S.J., 2015, Comparison of thermal performance between plate-fin and pin-fin heat sinks in natural convection, International Journal of Heat Mass Transfer, 83, 23, 345-356

11. Keshavarz Moraveji M., Mohammadi Ardehali R., Ijam A., 2013, CFD investigation of nanofluid effects (cooling performance and pressure drop) in mini-channel heat sink, International Communication in Heat Mass Transfer, 40, 1, 58-66 
12. Khanna P., Bhatnagar S., Gust W., 1999, Analysis of packaging and sealing techniques for microelectronic modules and recent advances, Microelectronics International, 16, 2, 8-12

13. LeE M., Kim H.J., Kim D.K., 2016, Nusselt number correlation for natural convection from vertical cylinders with triangular fins, Applied Thermal Engineering, 93, 18, 1238-1247

14. Loh C.K., Chou D.J., 2004, Comparative analysis of heat sink pressure drop using different methodologies, 20th IEEE Semi-Therm Symposium

15. Masuko T., Takeda S., 2009, Die attach adhesive and films, Materials for Advanced Packaging, Springer, Boston, MA

16. Micheli L., Reddy K.S., Mallick T.K., 2016, Experimental comparison of micro-scaled plate-fins and pin-fins under natural convection, International Communications in Heat and Mass Transfer, $\mathbf{7 5}, 3,59-66$

17. Poulikakos D., Bejan A., 1982, Fin geometry for minimum entropy generation in forced convection, Journal of Heat Transfer, 104, 4, 616-623

18. Salwe A., Bhagat A.U., Gabhane M.G., 2014, Comparison of forced convective heat transfer coefficient between solid pin fin and perforated pin fin, International Journal of Engineering Research and General Science, 2, 3, 2091-2730

19. Shanmugan S., Mutharasu D., Lee Y., 2014, Surface and electrical properties of plasma processed RF sputtered GaN thin film, European Physical Journal of Applied Physics, 68, 3, 52-56, 30303, DOI: 10.1051/epjap/2014140225

20. Torit K., KwAK K.M., Nishino K., 2002, Heat transfer enhancement accompanying pressure-loss reduction with winglet-type vortex generators for fin-tube heat exchangers, International Journal of Heat Mass Transfer, 45, 13, 3795-3801

21. Wong C., Clegg D., Kumar A., Ostsuka K., Ozmat B., 1997, Package sealing and encapsulation, Microelectronics Packaging Handbook, Springer 